\title{
Is UV Ornamentation an Amplifier in Swordtails?
}

\author{
MOLLY E. CUMMINGS, ${ }^{1}$ FRANCISCO J. GARCÍA DE LEÓN, ${ }^{2}$ DIANE M. MOLLAGHAN, ${ }^{1}$ \\ and MICHAEL J. RYAN ${ }^{1}$
}

\begin{abstract}
Do distinct male morphs use the same ornaments in different ways? Female preference for UV ornamentation and male activity was examined in two different male size classes of the swordtail Xiphophorus nigrensis: intermediate and large. UV ornamentation is preferred by females for both size classes, while high male activity is not. Large males have significantly greater intensity and saturation of UV reflectance for several body regions. Despite this difference in signal strength, intermediate sized males garnered a greater gain in female attention for UV ornamentation relative to large males. The differential payoff may be a result of different interactions between ornamentation and activity between the size classes. Females show significant preference for UV-ornamented intermediate males only when they are more active than their rival and not when the UV-ornamented male is less active, indicating that behavior might serve as an amplifier of UV ornamentation in this class. Meanwhile, large males gain from their UVornamentation only when they are less active than their rival, failing to support behavior as an amplifier for UV ornamentation in this size class. This interaction between size class and activity is significant, and suggests that UV and/or behavior play different roles for alternative male morphs competing for female attention.
\end{abstract}

\section{INTRODUCTION}

$\mathbf{P}$ OLYGYNOUS MATING SYSTEMS are characterized by elaborate male traits, and in many instances suites of such traits have evolved to increase female attention. ${ }^{1-3}$ Polygynous mating systems can also have alternative mating strategies in which one type of male typically exhibits stealthy and inconspicuous behavior to acquire matings as opposed to the conspicuousness usually associated with courting or territorial males (e.g., Warner and Robertson, ${ }^{4}$ Gross $^{5}$ ). It is unusual for alternative male morphs to have the same suite of signaling traits. Here we explore the function of some of the traits that two male morphs share in a species of northern swordtails (Xiphophorus nigrensis), and determine whether signals function differently between male morphs.

Swordtails and platyfish, members of the genus Xiphophorus, have male sexual matura- tion regulated by a single genetic factor, the pituitary or $\mathrm{P}$ gene, producing distinctive male size classes varying by genotype within species. ${ }^{6,7}$ One species of northern swordtails, $X$. nigrensis, has three male morphs that vary in size-specific suites of physical and behavioral traits (small, intermediate, and large; reviewed in Kallman $\left.{ }^{8}\right)$. Small males $(<26 \mathrm{~mm}$ standard length (SL)) are phenotypically more similar to females than other male morphs. They exhibit a sneaking strategy that lacks conspicuous courtship displays and they chase females and acquire matings via force copulations. ${ }^{9}$ The other two size classes rely on suites of secondary sexual traits to attract females including swords (extension of lower caudal fin rays), size, coloration, and ornamental bars. ${ }^{9,10}$ Behavioral traits between these two classes differ, however. Large males (>31 mm SL) exhibiting almost no 'chasing' behavior and rely on stereotyped courtship to attract females,

\footnotetext{
${ }^{1}$ Section of Integrative Biology, University of Texas, Austin, Texas.

${ }^{2}$ Centro de Investigaciones Biológicas del Noroeste, La Paz, Mexico.
} 
while intermediate males (26-31 mm SL) exhibit a combination of both chasing and courtship. ${ }^{9}$ Here we explore whether multicomponent signaling features (UV and male activity) have differential effects by size class.

The functions of multicomponent signals can be varied and are still not well understood. 3,11-19 Possible functions include, for example, independent signals, redundant signals, and amplifying components of signals. Amplifying can occur between fixed (e.g., ornamentation) and flexible (e.g., behavioral) cues ${ }^{20,21}$ when behavioral displays amplify, that is improve, the detection or discrimination of ornamental traits, such as the red ventral coloration in threespine sticklebacks ${ }^{22}$ or when ornamental traits serve the detection of courtship displays. ${ }^{23}$

Here we examine the interaction of male UV ornamentation and activity rates in two size classes in X. nigrensis to determine whether UV acts as an amplifier for accentuating behavioral displays or vice versa. We perform this test in two size classes of swordtails that vary in their reproductive behavior: large and intermediate sized males. We standardize behavior between these two classes of males by overall activity rates.

To determine if activity or UV ornamentation amplify one another we first determine the effect of each, independently, on female preference. We then examine their specific interactive effects to examine three alternative sets of interaction. (1) Activity and UV have independent effects on preference: if so, their influence on male attractiveness should be additive. (2) UV amplifies activity: this interaction predicts that UV ornamentation influences preference only when males are more active, with no preference for this ornamentation when males show little activity. (3) Activity amplifies UV ornamentation: we predict preference for higher activity rates only when UV is visible, and no preference for activity without UV ornamentation.

\section{RESULTS}

\section{UV ornamentation}

The forty female $X$. nigrensis we tested preferred UV ornamented males (Fig. 1). The ef-

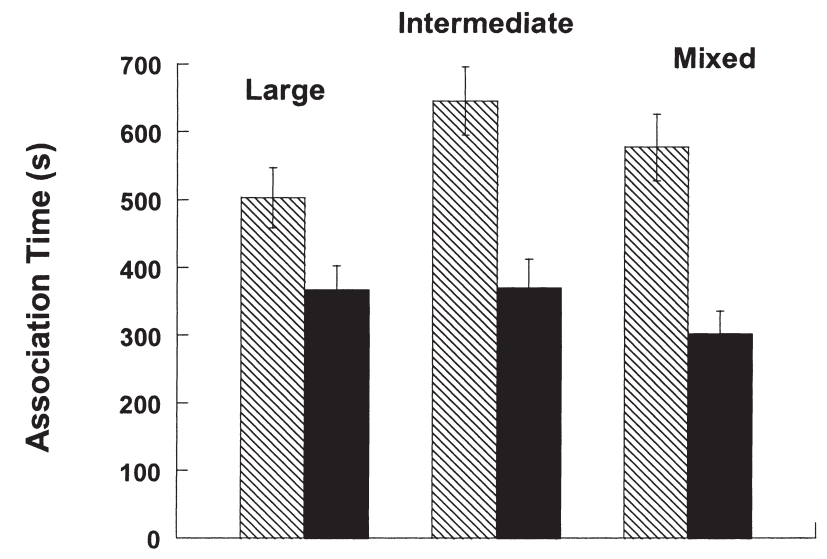

FIG. 1. Mean female association time in UV-transmittant (UV+; cross-hatched bars) and UV-blocking (UV-, black bars) sides of tank for three different experiments (each with $n=20$ females): large males only; intermediate males only; and mixed male size classes. ${ }^{24}$

fect however, was stronger for females choosing between intermediate-sized males. Females that observed intermediate male pairs spent significantly more time viewing males with visible UV ornamentation than when it was invisible $(n=20$ females; mean (sec) \pm 1 SE (standard error) UV-transparent $\left(\mathrm{UV}^{+}\right)=$ $644.8 \pm 50.1 ; \mathrm{UV}-$ blocking $\left(\mathrm{UV}^{-}\right)=369.2 \pm$ 42.6; paired $\left.t=3.12 ; \mathrm{p}_{(2 \text {-tail })}=0.006\right)$. Meanwhile, another group of females observing large males showed only a marginally significant preference for UV ornamented males $(n=$ 20 females; $\mathrm{UV}^{+}=502.8 \pm 43.9 ; \quad \mathrm{UV}^{-}=$ $367.1 \pm 35.4$; paired $\left.t=2.06 ; \mathrm{p}_{(2 \text {-tail })}=0.053\right)$. Neither set of females showed a significant preference for the UV-transparent side of the tank in the pre-test control (intermediate male experimental control $\mathrm{UV}^{+}=209.2 \pm 20.0$; $\mathrm{UV}^{-}=166.8 \pm 18.4$; paired $t=1.69 ; \mathrm{p}_{(2 \text {-tail })}=$ 0.106; large male experimental control: $\mathrm{UV}^{+}=$ $163.15 \pm 33.22 ; \mathrm{UV}^{-}=150.1 \pm 30.2$; paired $t=$ $\left.0.278 ; \mathrm{p}_{(2 \text {-tail })}=0.784\right)$.

When we examine the same data from the $X$. nigrensis males' perspective, we see that intermediate males gain more female attention from their UV ornamentation than large males (Fig. 2 ). We examined the relative advantage of UV ornamentation for $24 \mathrm{X}$. nigrensis males by examining the increase in female association time each male experienced while viewed behind UV-transparent filters relative to UV-blocking filters across three experiments. Males in all 


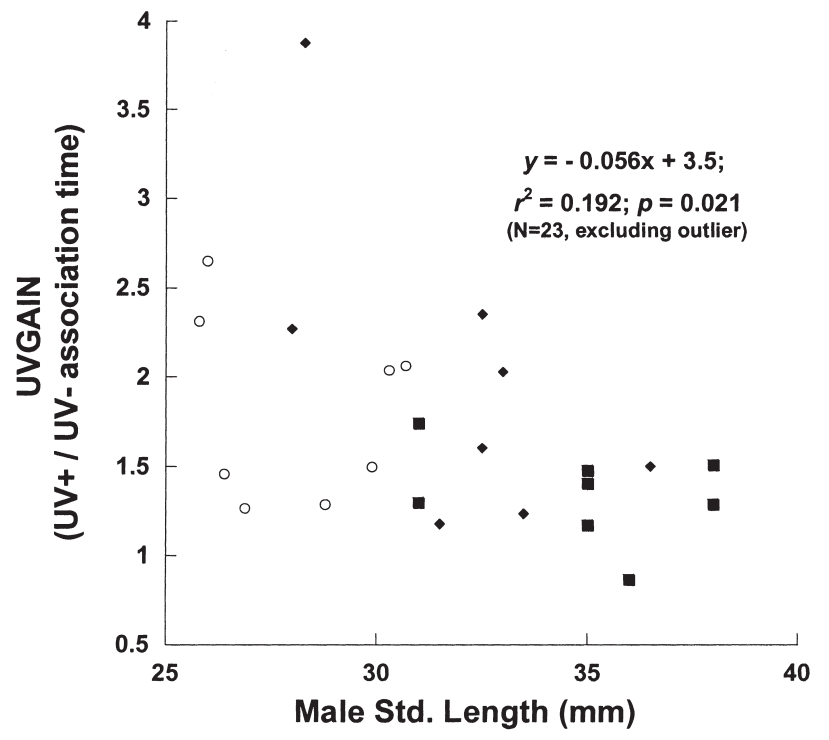

FIG. 2. Total gain in female association time by UVviewing environment by male size (standard length) across three experiments ( $n=24$ males, $n=60$ trials $/ \mathrm{fe}-$ males). Each symbol represents the UVGAIN (total association time females spent viewing each male behind UVtransparent plexiglass/total association time behind UV-blocking filters across 5 females (trials). The standard length $(\mathrm{mm})$ of each experimental male is shown on $X$ axis, representing intermediate $(\bigcirc)$ and large $(\boldsymbol{\square})$ males from experiments presented here, as well as a previous experiment including both male size classes $(\diamond)$ from Cummings et al. ${ }^{24}$

three experiments: 8 intermediate +8 large class males from the above experiments; 2 intermediate +6 large males from Cummings et al. ${ }^{24}$ were viewed by 5 different females for 10 min with their UV ornamentation visible (viewed behind UV-transparent filters) and 10 min with their UV ornamentation invisible (viewed behind UV-blocking filters). The increase in female association time that intermediate males experienced across five trials while viewed behind UV-transparent filters was greater than that of large males: mean \pm SE net preference for UV (total association time $\mathrm{UV}+/$ total association time $\mathrm{UV}-$ ) for large males $=1.47 \pm 0.10, n=14$; for intermediate males $=2.46 \pm 0.38, n=10$. The negative relationship between male size and net preference for UV ornamentation (UVGAIN) is highly significant $(n=24$ males tested in 60 female choice trials, $\mathrm{y}=-0.12 \times+5.673 ; \mathrm{F}_{1,22}=6.44 ; r=$ $0.226 ; \mathrm{p}=0.019)$. This relationship is still statistically significant when removing the male with the greatest net preference for UV, a potential outlier: $n=23, \mathrm{y}=-0.108 \times+5.204$, $\mathrm{F}_{1,21}=8.87 ; r^{2}=0.297 ; \mathrm{p}=0.007$ (Fig. 2).

The differential payoff in UV ornamentation between the size classes is not predicted by differences in UV ornamentation between large and intermediate males. In fact, large males have greater intensity UV(log), and saturation UV(prop), of UV reflectance than the intermediate males in several body regions (Table 1). Furthermore, large males have significantly more UV reflectance than intermediate males in areas that are sexually dimorphic and dichromatic (sword area and flank). Within intermediate-sized males, there was an overall increase in UV reflectance. The UV composite

Table 1. Tho-Sample $t$ Tests of Reflectances by Size Class with Pooled Variance

\begin{tabular}{|c|c|c|c|c|c|}
\hline Body area & & $\begin{array}{l}\text { Intermediate } \\
\quad \mathrm{x}( \pm \mathrm{SE})\end{array}$ & $\begin{array}{c}\text { Large } \\
\mathrm{x}( \pm \mathrm{SE})\end{array}$ & $t_{d f}$ & $\mathrm{P}$ \\
\hline L. Caudal & $\begin{array}{l}U V(\log ) \\
U V(\text { prop })\end{array}$ & $\begin{array}{l}2.41 \pm 0.09 \\
0.07 \pm 0.01\end{array}$ & $\begin{array}{l}2.77 \pm 0.07 \\
\mathbf{0 . 1 3} \pm 0.01\end{array}$ & $\begin{array}{l}3.2_{30.3} \\
3.6_{33.7}\end{array}$ & $\begin{array}{l}0.031 \\
0.010\end{array}$ \\
\hline Ventral & $\begin{array}{l}U V \text { (log) } \\
U V \text { (prop) }\end{array}$ & $\begin{array}{l}2.97 \pm 0.07 \\
0.18 \pm 0.01\end{array}$ & $\begin{array}{l}3.03 \pm 0.04 \\
0.23 \pm 0.01\end{array}$ & $\begin{array}{l}0.5_{28.3} \\
3.3_{31.0}\end{array}$ & $\begin{array}{l}1.000 \\
0.026\end{array}$ \\
\hline Midline & $\begin{array}{l}U V(\log ) \\
U V(\text { prop })\end{array}$ & $\begin{array}{c}2.6 \pm 0.07 \\
0.16 \pm 0.01\end{array}$ & $\begin{array}{l}2.52 \pm 0.06 \\
0.26 \pm 0.02\end{array}$ & $\begin{array}{l}0.9_{34.1} \\
4.9_{43.6}\end{array}$ & $\begin{array}{r}1.000 \\
<0.001\end{array}$ \\
\hline Flank & $\begin{array}{l}U V(\log ) \\
U V(\text { prop })\end{array}$ & $\begin{array}{l}2.51 \pm 0.09 \\
0.14 \pm 0.02\end{array}$ & $\begin{array}{l}2.93 \pm 0.05 \\
0.22 \pm 0.01\end{array}$ & $\begin{array}{l}4.1_{22.5} \\
3.4_{21.2}\end{array}$ & $\begin{array}{l}0.005 \\
0.025\end{array}$ \\
\hline Operculum & $\begin{array}{l}U V(\log ) \\
U V \text { (prop) }\end{array}$ & $\begin{array}{l}3.45 \pm 0.08 \\
0.25 \pm 0.01\end{array}$ & $\begin{array}{l}3.49 \pm 0.07 \\
0.21 \pm 0.01\end{array}$ & $\begin{array}{l}0.4_{29.4} \\
2.9_{25.4}\end{array}$ & $\begin{array}{l}0.732 \\
0.079\end{array}$ \\
\hline
\end{tabular}

$\mathrm{P}=$ Bonferoni-corrected significance; $\mathrm{N}=8$ (intermediate), $\mathrm{N}=8$ (large). 
score for all body areas (average UVlog + UVprop) exhibited a significant relationship with body size $\left(\mathrm{y}=0.094 \times+0.317, r^{2}=0.707\right.$, $\left.\mathrm{F}_{1,6}=14.51, \mathrm{p}=0.009\right)$. However, the large class males showed no increase in UV reflectance scores across large male body size $\left(\mathrm{y}=-0.016 \times+3.81 ; \mathrm{r}^{2}=0.126 ; \mathrm{F}_{1,6}=0.867\right.$, $\mathrm{p}=0.390$; Fig. 3). Individual differences in UV reflectance did not predict the amount of increased time females would associate with males during UV-transparent trials. UV composite reflectance scores showed no significant relationship with net preference for UV (UVGAIN) across males (intermediate males: $\mathrm{y}=-0.15 \times+2.268 ; \quad \mathrm{r}^{2}=0.005 ; \quad \mathrm{F}_{1,6}=0.027 ;$ $\mathrm{p}=0.874$; large males: $\mathrm{y}=-0.92 \times+4.36 ; \mathrm{r}^{2}=$ $\left.0.184 ; F_{1,6}=1.36 ; p=0.290\right)$. Furthermore, the amount of UV ornamentation each male had relative to his paired rival also did not account for variation in UVGAIN $(\mathrm{y}=-0.027 \times+1.58$, $\left.\mathrm{r}^{2}=0.0002 ; \mathrm{F}_{1,14}=0.002, \mathrm{p}=0.960\right)$.

\section{Male activity}

When viewing pairs of males, females did not show a preference for individual males that displayed a higher rate of activity relative to their paired rival. In the intermediate male experiment, females spent an average $( \pm$ SE) of

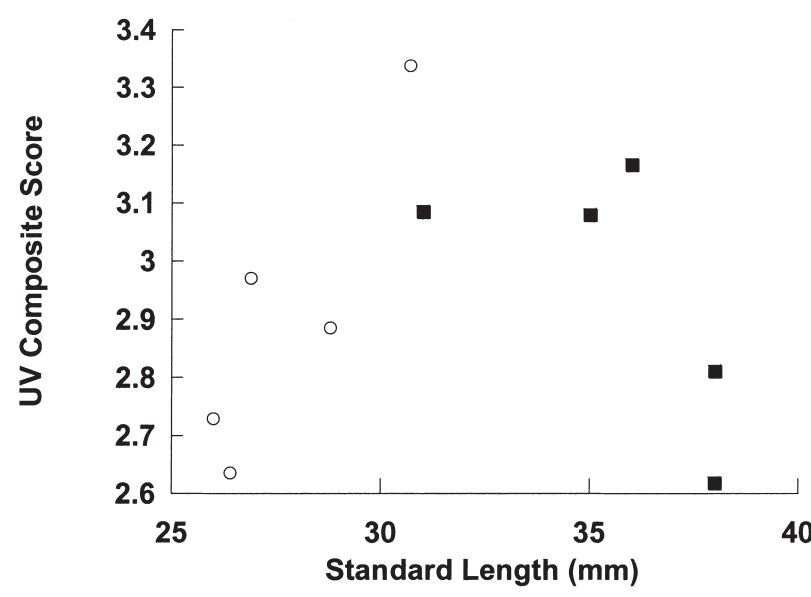

FIG. 3. UV composite score by male size (standard length) across intermediate male only and large male only experiments. Each symbol represents the UV composite Score representing the average UVlog reflectance + average UVprop for each body area. The standard length $(\mathrm{mm})$ of each experimental male is shown on $X$ axis, representing intermediate $(\bigcirc)$ and large $(\square)$ males from experiments presented.
$275.29 \pm 20.71$, with males showing higher activity rates, and only $225.27 \pm 20.23$ with lower activity rate males $(n=37$, excluded trials where only one male was visited per $10 \mathrm{~min}$ observation; paired $\left.t=1.274, \mathrm{p}_{(2 \text {-tail })}=0.211\right)$. And in the large male experiment, females spent an average of $190.82 \pm 16.17$ with more active males, and $235.31 \pm 16.45$ with the less active males $\left(n=39\right.$, paired $t=1.72 ; \mathrm{p}_{(2 \text {-tail })}=$ 0.093).

Large and intermediate males did not alter their activity rate depending on the UV filter they were viewed behind; however, the two classes differed significantly in terms of mean activity rate. Both intermediate and large males displayed similar levels of activity whether they were viewing females behind a UV-transparent or UV-blocking filter (intermediate males: mean activity rate $\pm \mathrm{SE}$ behind $\mathrm{UV}^{+}=$ $0.022 \pm 0.003, \mathrm{UV}^{-}=0.019 \pm 0.003, n=37$ (excluded trials where only one male was visited per $10 \mathrm{~min}$ observation); paired $t=0.914$, $\mathrm{p}_{(2 \text {-tail })}=0.367$; large males, $n=38$ observations; $\mathrm{UV}^{+}=0.010 \pm 0.002, \mathrm{UV}^{-}=0.014 \pm$ 0.002 , paired $\left.t=1.31, \mathrm{p}_{(2 \text {-tail })}=0.198\right)$. Intermediate males, however, displayed a significantly greater activity rate than large class males (intermediate male mean activity rate $=0.021 \pm$ 0.002 , large male mean activity rate $=0.012 \pm$ $\left.0.002, t=3.46, \mathrm{p}_{(2 \text {-tail })}<0.001\right)$.

\section{$U V$ and activity interactions}

For the intermediate and large class experiments described above, we examined the relationship between male activity and UV ornamentation using pairwise comparisons between males that differed by activity and UV ornamentation. The attractiveness, as measured by female association time, of relative male activity varied by the visibility of UV ornamentation but in opposing directions between the two size classes. Intermediate males gained significant increase in female attention when they were both the more active and UV ornamented male (Fig. 4): mean association time \pm SE: Act $+\quad \mid$ UV $+=322.63 \pm 25.91$; Act $-\mid \mathrm{UV}-=175.15 \pm 22.67, n=19, t=$ $3.207, \mathrm{p}_{(2 \text {-tail })}=0.005$.

Large males exhibited an entirely different pattern of attractiveness relationship between 
INTERMEDIATE MALES

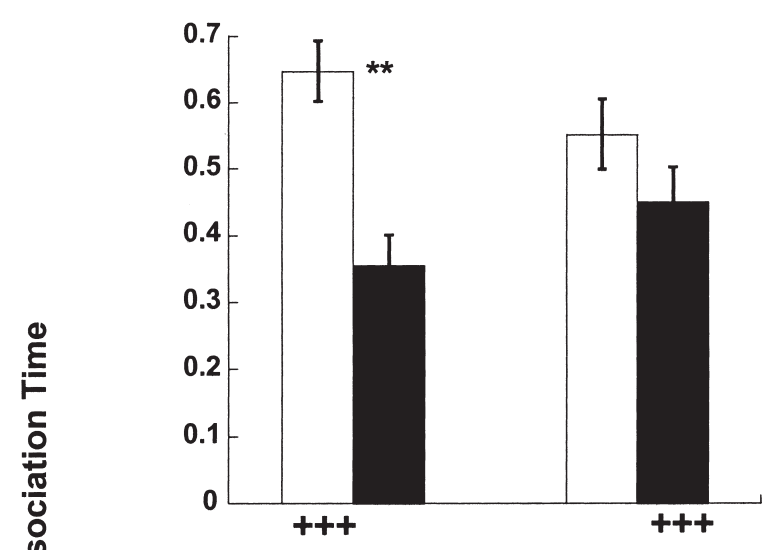

LARGE MALES

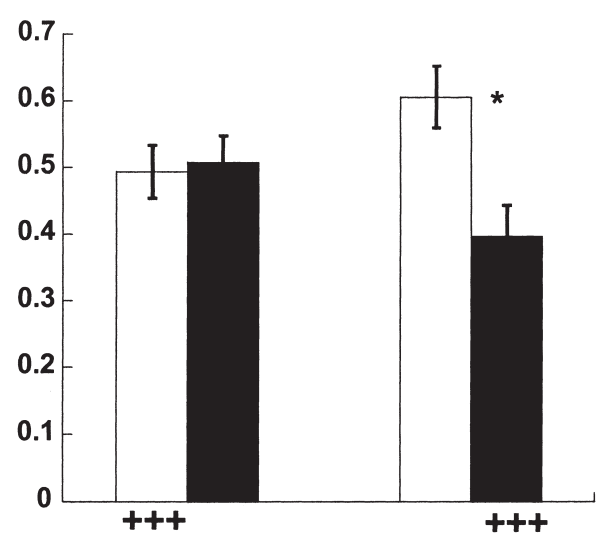

FIG. 4. Proportion of female association time with males behind UV-transparent plexiglass (UV+; white bars) and UV-blocking (UV+; black bars) filters according to relative activity $(+++=\mathrm{ACT}+$, more active male) and by size class (A) intermediate, (B) large.

UV ornamentation and male activity. Large males received no benefit from being both UVornamented and the more active male of a pair (Fig. 4): Act $+\mid \mathrm{UV}+=223.74 \pm 20.27$; Act $-\mid$ $\mathrm{UV}-=226.95 \pm 18.6, n=19, \quad t=1.73, \quad \mathrm{p}_{(2-}$ tail) $=0.925$. The gain for UV ornamentation for large males appears when these males are less active than their paired rival: Act $-\mid \mathrm{UV}+=$ $243.25 \pm 27.14$, and Act $+\mid \mathrm{UV}-=159.55 \pm$ 23.33, $n=20, t=2.21, \mathrm{p}_{(2 \text {-tail })}=0.039$.

Whereas both males enjoyed more attention from females when UV ornamentation was visible, male activity increased UV attractiveness for one class, and decreased UV attractiveness in the other. A three-way ANOVA was com-
A. puted to examine the relationship between UV filter, activity, and size class on proportion of female association time. The ANOVA showed only one significant main effect for UV filter $(\mathrm{F}=20.338, \mathrm{p}<0.001)$; and only one significant interaction effect between activity and size class $(\mathrm{F}=9.998, \mathrm{p}=0.002)$.

\section{DISCUSSION}

UV ornamentation serves to attract female attention for males of both intermediate and large size classes of $X$. nigrensis (Fig. 1). Our results confirm previous studies indicating the importance of ultraviolet ornamentation as a B. preferred trait in sexual communication (e.g., insects, ${ }^{25,26}$ birds, $^{27}$ guppies, ${ }^{28,29}$ and swordtails ${ }^{24}$ ). What is unique to our study is that we show that UV ornamentation is a preferred trait among males belonging to two different genotypic-morphs (intermediate and large class males). Other systems with alternative male mating morphs rely on different traits or tactics to gain access to females, here we have distinct morphs using the same trait to attract female attention. While UV ornamentation is presumably a sexually selected trait for both classes, there is differential expression of this trait with large males exhibiting greater UV ornamentation than intermediate males (Table 1). UV is a sexually dimorphic trait, ${ }^{24}$ and one that is class-dimorphic between competing male morphotypes.

Large males have more body regions with greater UV intensity and saturation, however, the relative influence of this UV ornamentation on female preference does not vary proportionately. Intermediate males enjoyed a greater increase in female attention than large males when their UV ornamentation was visible to females (Fig. 2). Thus swordtails represent a system with two alternative male mating morphs that have differential payoffs for the same sexually preferred trait.

The differential payoff of UV ornamentation between the male size classes may be driven by differential effects of activity on UV attractiveness. For intermediate males, there is a positive interaction between male activity level and UV ornamentation attractiveness (Fig. 4). Female 
swordtail response to this class of males is similar to guppy females (Poecilia reticulata) in exhibiting a preference strongly biased by a male's display. ${ }^{16,30,31}$ For large class males however, UV was only attractive when males were less active than their paired rival (Fig. 4). These experiments demonstrate that there is an intersignal interaction that varied by size class across the two courting size classes in $\mathrm{X}$. nigrensis.

We expect interactions between male signals when one of them is serving to amplify the other. Various studies examining signal interactions have shown that ornaments amplify behavioral displays (as in wolf spiders ${ }^{23}$ ) or behavioral displays amplify ornaments (as in sticklebacks ${ }^{22}$ ). Hasson ${ }^{20}$ introduced the concept of amplifiers using a population genetics model based on male display as an amplifier of a viability-indicating trait to illustrate the relationship between amplifiers and preferred traits. He found that displays can evolve as a result of their amplifying effect for another trait that is already preferred by females. His work also noted that while the amplified trait should be attractive to females, the amplifier itself need not be. Our data on UV ornamentation and activity in X. nigrensis shows that UV is a preferred trait across male morphs, while activity is not independently attractive to females. These results indicate that UV is not amplifying behavior; however, it leaves open the possibility that activity may amplify UV ornamentation.

Figure 4 allows us to dissect this possibility between the two male size classes. For the intermediate class, activity appears to be amplifying UV ornamentation as the results meet our predictions for an amplifier in that activity is only preferred when paired with UV ornamentation. And although activity is not independently attractive in this system, preference for males increases in an additive fashion: lowest preference seen in UV-blocked less active males, followed by UV-blocked more active males, followed by UV-ornamented less active males, and finally the highly attractive combination of UV-ornamented more-active males. This sequence of additive attraction does not describe the pattern of female preference for UV and activity of large males. Large class males have an opposite relationship between UV ornamentation and activity level and their interactive effect on female viewing time relative to intermediate males. For large class males, activity level is not serving to amplify male UV ornamentation as UV ornamentation is only preferred among males that are less active than their rival (Fig. 4). While these results are surprising in general, it may be less surprising if we examine signal saliency associated with this experimental behavior across the male size classes.

Intermediate males have less UV reflectance than large class males on most body parts (Table 1, Fig. 3), however the particular behavioral display exhibited in this experiment may highlight the one area with the greatest UV reflectance, the operculum. Using the updown movements as a measure of activity, a more active intermediate male will spend more of his time facing the filter with his operculum directly facing the female while a less active male may be positioning himself with other less UV-ornamented areas of his body more noticeable to the female. Meanwhile large males that are not performing repeated up-down filter-facing movements may allow females to view other body regions that have significant UV ornamentation. Our measurements here show that many of these side-viewing body areas are class-dimorphic in UV reflectance (Table 1), and previous measurements indicate that many of these regions are also sexually dichromatic in the UV waveband. ${ }^{24}$ Hence, females might achieve a better view of a large male's UV ornamentation when he is not performing this movement. Nevertheless, our experiments do not rule out the possibility that sterotypic courtship displays as performed in open aquaria environments ${ }^{9}$ may serve as amplifiers of UV ornamentation. Future experiments that allow for free interactions between males and females in UV-manipulated environment may help address this possibility.

It appears that sword tail males experience a trade-off for obtaining female attention: large males are less active yet have more UV ornamentation, while intermediate males are more active and have less UV. Large male swordtails have evolved high UV signal without behavioral amplification. Meanwhile, intermediate 
males use behavior to amplify their UV ornamented traits to females. The trade-off between size and activity shown here in swordtails has been found in some guppy populations, where Rodd and Sokolowski ${ }^{32}$ found a negative relationship between courtship and body size, with small males displaying more often than large males. The possibility that similar factors play a role in alternative male morphs of $X$. nigrensis should be investigated. Perhaps, the interaction between behavior and ornament, although negative for large class males, may represent a successful strategy for this male size class to maximize female attention and minimize predatory reaction in this system? Furthermore, the possibility that males differ in ornament expression and behavioral amplification may be due to a number of possible 'receivers' (predators, females, or other males ${ }^{33}$ ) also needs to be considered. Only further investigation involving more levels of natural complexity (e.g., predators) will allow us to test these ideas and shed more light on the complex world of multicomponent signaling.

\section{METHODS}

\section{Quantifying UV preference}

We quantified male behavioral activity and female preference for size-matched pairs of intermediate and large males in UV-transmitting and UV-blocking viewing environments. The experimental tank and protocol is identical to the dichotomous choice test used in Cummings et al. ${ }^{24}$ We divided the aquarium into three sections with individual males confined to the left and right end chambers behind either a $\mathrm{UV}^{+}$ filter (UV-transmittant Rhöm Plexiglas GS 2458 with Gam 10-40) or $\mathrm{UV}^{-}$filter (UV-blocking UVGG-400 SCHOTT). The $\mathrm{UV}^{+}$plexiglas passed full-spectrum $(300-700 \mathrm{~nm})$, and the $\mathrm{UV}^{-}$plexiglass blocked only UV wavelengths allowing human visible range to pass (400-700 $\mathrm{nm})$. We illuminated the aquarium with two $500 \mathrm{~W}$ Quartz-halogen lamps with the safety (UV-absorbing) glass removed and oriented at a Teflon sheet that reflected the light diffusely over the experimental tank. This diffuse light was then filtered by a combination of gel filters (Gam 1532, Roscolux 365, and Cinegel 4360) be- fore entering the experimental tank to recreate the downwelling light conditions measured in this species' native habitat. ${ }^{24}$ Each end of the tank also had Teflon plus gel filters (Lee 725, Cinegel 4330) placed against the back wall and side sections of the male compartments to recreate the sidewelling spectral conditions measured in their native environment. On the UV-transmittant side of the tank, we added a diffusion filter to the spectral filter set to account for differences in intensity between the two sides (UV-block, and UV-transmittant). We equalized total intensity differences between the two sides of the tank by adding a diffusion filter (Gam 1040) to the downwelling filter set on the $\mathrm{UV}^{+}$side of the tank that equalized the total flux between the two sides of the tank. ${ }^{24}$

Test animals were from the nacimiento of the Rio Choy, San Luis, Potosi, Mexico, or recent descendents of this population maintained in large, outdoor tanks at Brackenridge Field Laboratories, Austin, Texas. Forty female X. nigrensis were tested in a $120 \mathrm{~cm} \times 30 \mathrm{~cm} \times 48$ $\mathrm{cm}$ aquarium. Twenty of these were tested with intermediate-sized males and twenty with large-sized males. To ensure receptivity in female subjects, female and male fish were sexually isolated at least 20 days prior to testing. Four pairs of large class sworded male $X$. nigrensis, and four pairs of nonsworded intermediate-sized male $X$. nigrensis, were matched for standard length (SL) and total length (including sword-length). Each pair was tested for UV ornamentation preference by five female $X$. nigrensis.

Each female preference test included three 10 min observation trials: a pretest control (where no males were present in the tank), and two 10 min treatment periods with a pair of males present. Each trial began with a 5 min acclimation period where a female was confined in the central region in an opaque cylinder. After acclimation period, the cylinder was removed and for $10 \mathrm{~min}$, female time spent in each of three sections (two end-zones, and a central neutral zone with plastic plant) was recorded with stopwatches. After the control period, males were introduced to each endzone of the tank: one behind an UV + filter, and the other behind an $\mathrm{UV}^{-}$filter. After 10 min of female observation, the filters were switched and female 
association time recorded again. We recorded the amount of time females spent in the $24 \mathrm{~cm}$ sections nearest individual males as her association time and used this as a measure of mate choice preference. ${ }^{34-36}$ Females that spent greater than $80 \%$ of time for all three observation periods (control and two male treatments) on the same side of the tank were identified as side-biased, those data were removed from the study, and the females were kept in isolation and retested at a later date $(n=2$ females, intermediate study only). To quantify female preference for male UV ornamentation, we pooled the two 10 min observation periods and assessed the total association time each female spent viewing males behind UV + verses UVfilters using a paired $t$ test $(n=20$ for each experiment).

\section{Male behavior}

The UV filters used to manipulate male UV ornamentation prohibited physical contact between males and females, but males and females interacted visually on each side of the filter. We quantified male behaviors to obtain a measure of activity. It is important to note, however, that males could not perform the full sexual or courtship display in this experimental setup, since this behavior involves the male bending his body in the shape of a " $\mathrm{C}$ " around the front of the female. ${ }^{9}$

For the first experiment involving large males, behaviors recorded with an event recorder (provided by C. Patton of Hopkins Marine Station, Behave.exe) included: 'updown movements' (vertical swim to the surface and back down while his snout is facing or touching the filter directly across from the female), rapid jerks (rapid movements of head or body), shimmy (quick tilting of the full body side-to-side), fin display (dorsal and/or anal fin erect), and circle (horizontal swim along bottom towards back of tank or spiraling up towards surface).

The most common male behavior in this experimental arena was the 'up-down movement'. It was often made repeatedly by males, and was exhibited more often than any other by at least a 5:1 ratio (frequency totals across 8 males in the 40 10-min trials): Up-Down-Move- ments: 179; Rapid Jerks: 31; Shimmy: 10; Fin Display 7, Circle: 7. The up-down-movement was also the only behavior performed by all males in the study. This behavior appears to be an attempt of the male to approach and make contact with the female on the opposite side of the filter barrier.

Male behavioral data were collected concurrently with female association time data. Since male behaviors were only recorded when females were associating with them, a measure of activity rate rather than absolute numbers of behaviors was used for comparisons. Activity rate was calculated as the number of up-down-movements per viewing second. To quantify female preference for male activity, we compared differences in male activity rate between paired males and female viewing time in each 10 min observation periods since male behavior rate could vary between the two successive $10 \mathrm{~min}$ observation trials ( $n=40$ possible trials per experiment) using paired $t$ tests. Any $10 \mathrm{~min}$ observation trials where females failed to visit one of the males were removed from the preference for male activity evaluation.

To investigate the interaction between UV ornamentation and activity rate, we divided all experimental observation periods $(n=40$ per size-specific experiment, representing two 10 min observation periods per female trial) into four possible activity. UV ornamentation categories including: (a) (Act +$) \mid(\mathrm{UV}+)$ representing males exhibiting higher activity rates than their paired rival while being viewed behind $\mathrm{UV}+$ filters; (b) (Act+) $\mid(\mathrm{UV}-)=$ Greater Activity | behind UV- filters; (c) (Act-) | $(\mathrm{UV}+)=$ Lesser Activity $\mid \mathrm{UV}$ present; and (d) $($ Act -$) \mid(\mathrm{UV}-)=$ Lesser Activity $\mid \mathrm{UV}$ absent.

\section{Reflectance spectrometry}

Following each behavioral experiment, we measured the spectral reflectance of all males $(n=16)$ as in the previous study, ${ }^{24}$ using a portable spectrometer (EPP2000C-UV+VIS, StellarNet Inc., Tampa, FL) a full spectrum (UV-VIS) regulated light source (Xenon arc lamp, model 6255, Oriel, Stratford, CT), and a sighting optic described elsewhere ${ }^{37}$ with a fused silica double convex $25.4 \mathrm{~mm}$ diameter 
lens (UV DCX L08-016, Edmund Scientific, Tonawanda, NY) to transmit the light onto a $400 \mu \mathrm{m}$ (UV-VIS, Ocean Optics, Inc., Dunedin, FL) receiving fiber. We measured all males using the same incident light angle $\left(25^{\circ}\right.$ off normal) and collection angle (sighting optic positioned directly parallel to side of fish to mimic a viewing female). We collected spectral measurements from a variety of body regions with at least two measurements per location per male. The total number of spectral measurements per size class includes: ventral regions along flank (intermediate $=16$, large $=16$ ), midflank line (intermediate $=16$, large $=30$ ); flank regions above midline (intermediate $=$ 16 , large $=20$ ); operculum (intermediate $=16$, large $=16$ ); lowest caudal rays (base of sword; intermediate $=16$, large $=22$ ). We evaluated male reflectances in terms of their UV component for both UV intensity (UV(log): log of the total UV flux: $\log (\Sigma R(300-399 \mathrm{~nm}))$, and UV saturation (proportion of UV wavelengths relative to total reflectance: prop UV: ( $\Sigma R 300$ 399)/(¿R300-700)). We calculated an overall UV composite score for each male which represented the average UVlog and UVprop for all body areas. We used two sample $t$-tests assuming unequal variances (such variances were kept separate and the degrees of freedom appropriately reduced) to investigate statistical differences in UV reflectance measurements between intermediate and large males and adjusted significance testing for 10 sequential comparisons (Bonferoni corrections). This increase in UV association time was termed UVGAIN and represents the ratio of the total UV+ association time to the total UV - association time across all five females that viewed each male.

\section{ACKNOWLEDGMENTS}

The authors are grateful to Rose GelineauKattner, Sarah Holloway, and Robert Trevino for excellent assistance in the behavioral observation trials. We are also indebted to Brackenridge Field Laboratories for allowing us to maintain our stock populations of Xiphophorus; to NSF and Texas ARP for funding, and to the Mexican government for collection permits.

\section{REFERENCES}

1. Ryan MJ. Sensory systems, sexual selection, and sensory exploitation. Oxford Surveys Evol Biol1990;7: 157-195.

2. West-Eberhard MJ. Sexual selection and social behavior. In: Man and Beast Revisited. Robinson MH, Tiger L. (eds.) pp. 159-172, Smithsonian Institutional Press, 1991.

3. Möller AP, Pomankowski A. Why have birds got multiple sexual ornaments? Behav Ecol Sociobiol 1993;32:167-176.

4. Warner RR, Robertson DR. Sexual patterns in the labroid fishes of the western Caribbean, I: The wrasses (Labridae). Smithsonian Contrib Zool 1979;254:1-27.

5. Gross MR. Alternative reproductive strategies and tactics: diversity within sexes. Trends Ecol Evol 1996;11: 92-98.

6. Kallman KD, Schreibman MP. A sex-linked gene controlling gonadotrop differentiation and its significance in determining the age of sexual maturation and size of the platyfish, Xiphophorus maculatus. Gen Comp Endocrin 1973;21:287-304.

7. Kallman KD, Schreibman MP, Bordoski V. Genetic control of gonadotrop differentiation in the platyfish, Xiphophorus maculatus (Poeciliidae). Science 1973;181: 678-680.

8. Kallman KD. Genetic control of size at maturity in Xiphophorus. In: Ecology and Evolution of Livebearing Fishes (Poecillidae), Meffee GK, Snelson FF, (eds.), pp. 163-184, Drentra Hall. Englewod Cliffs, NJ. 1989.

9. Ryan MJ, Causey BA. "Alternative" mating behavior in the swordtails Xiphophorus nigrensis and Xiphopohus pygmaeus (Pisces: Poeciliidae). Behav Ecol Sociobiol 1989;24:341-348.

10. Ryan MJ, Rosenthal GG. Variation and selection in swordtails. In: Model systems in behavioral ecology, Dugatkin L (ed.), pp. 133-148. Princeton University Press. 2001.

11. Zuk M, Thornhill R, Ligon JD, Johnson K, Austad S, Ligon $\mathrm{SH}$, et al. The role of male ornaments and courtship behavior in female mate choice of red jungle fowl. Am Nat 1990;136:459-473.

12. Schluter D, Price T. Honesty, perception and population divergence in sexually selected traits. Proc R Soc Lond B 1993;253:117-122.

13. Endler JA, Houde AE. Geographic variation in female preferences for male traits in Poecilia reticulate. Evolution 1995;49: 456-468.

14. Marchetti M. The evolution of multiple male traits in the yellow-browed leaf warbler. Anim Behav 1998;55:361-376.

15. Partan S, Marler P. Behavior-communication goes multimodal. Science 1999;283:1272-1273.

16. Kodric-Brown A, Nicoletto PF. Female choice in the guppy (Poecilia reticulata): the interaction between male color and display. Behav Ecol Sociobiol 2001;50:346-351.

17. Elias DO, Mason AC, Maddison WP, Hoy RR. Seismic signals in a courting male jumping spider 
(Araneae: Salticidae). J Exp Biol 2003;206:4029_ 4039.

18. Candolin U. The use of multiple cues in mate choice. Biol Rev 2003;78:575-595.

19. Hebets EA. Attention-altering signal interactions in the multimodal courtship display of the wolf spider Schizocosa uetzi. Behav Ecol 2004;16:75-82.

20. Hasson O. Amplifiers and the handicap principle in sexual selection: a different emphasis. Proc R Soc Lond B 1989;235:383-406.

21. Hasson O. Sexual displays as amplifiers: practical examples with an emphasis on feather decorations. Behav Ecol 1991;2:189-197.

22. McLennan DA, McPhail JD. Experimental investigations of the evolutionary significance of sexually dimorphic nuptial coloration in Gasterosteus aculeatus (L.): the relationship between male colour and female behaviour. Can J Zool 1990;68:482-492.

23. Hebets EA, Uetz GW. Leg ornamentation and the efficacy of courtship display in four species of wolf spider (Araneae: Lycosidae). Behav Ecol Sociobiol 2000;47:280-286.

24. Cummings ME, Rosenthal GG, Ryan MJ. A private ultraviolet channel in visual communication. Proc R Soc B 2003;270:897-904.

25. Eisner T, Silberlied RE, Aneshansley D, Carrel JE, Howland HC. Ultraviolet video-viewing: the television camera as an insect eye. Science 1969;166: 1172-1174.

26. Silberglied RE. Communication in the ultraviolet. A Rev Ecol Syst 1979;10:373-398.

27. Andersson S, Amundsen T. Ultraviolet colour vision and ornamentation in bluethroats. Proc R Soc Lond B 1997;264: 1587-1591.

28. Kodric-Brown A, Johnson SC. Ultraviolet reflectance patterns of male guppies enhance their attractiveness to females. Animal Behav 2002;63,391-396.

29. Smith EJ, Partridge JC, Parsons KN, White EM, Cuthill IN, Bennett ATD, Church SC. Ultraviolet vision and mate choice in the guppy (Poecilia reticulata). Behav Ecol 2002;13:11-19.
30. Kodric-Brown A. Female choice of multiple male criteria in guppies: interacting effects of dominance, colouration and courtship. Behav Ecol Sociobiol 1993;32:415-420.

31. Nicoletto PF. Female sexual response to donditiondependent ornaments in the guppy, Poeciliia reticulate. Animal Behav 1993;46:441-450.

32. Rodd FH, Sokolowski MB. Complex origins of variation in the sexual behavior of male Trinidadian guppies, Poecilia reticulata: interactions between social environment, heredity, body size and age. Anim Behav 1995;49:1139-1159.

33. Andersson S, Pryke SR, Örnborg J, Lawes MJ, Andersson M. Multiple receivers, multiple ornaments, and a trade-off between agonistic and epigamic signaling in a widowbird. Am Nat 2002;160: 683-691.

34. Ryan MJ, Wagner W. Asymmetries in mating preferences between species: female swordtails prefer heterospecific mates. Science 1987;236:595-597.

35. Basolo AL. Female preference for male sword length in the green swordtail (Pisces: Poceciliidae). Animal Behav 1990;40:332-338.

36. Rosenthal GG, Evans CS. Female preference for swords in Xiphophorus helleri reflects a bias for large apparent size. Proc Natl Acad Sci USA 1998;95: 4431-4436.

37. Cummings ME. Modelling divergence in luminance and chromatic detection performance across measured divergence in surfperch (Embiotocidae) habitats. Vis Res 2004;44:1127-1145.

Address reprint requests to: Molly E. Cummings Section of Integrative Biology, CO930 University of Texas 2400 Speedway Austin, TX 78712

E-mail: mcummings@mail.utexas.edu 